\title{
Erratum to: Opportunities for improved promotion of ecosystem services in agriculture under the Water-Energy-Food Nexus
}

\author{
Andrew Bell ${ }^{1} \cdot$ Nathanial Matthews $^{2} \cdot$ Wei Zhang ${ }^{3}$
}

Published online: 22 December 2016

(C) AESS 2016

Erratum to: J Environ Stud Sci

DOI: 10.1007/s13412-016-0366-9

The original version of this article contained a mistake.

Figures 3 and 4 are reversed in the published article. The image appearing as Figure 3 is meant to be Figure 4, while the image appearing as Figure 4 is meant to be Figure 3.

The online version of the original article can be found at http://dx.doi. org/10.1007/s13412-016-0366-9.

Nathanial Matthews

n.matthews@cgiar.org

1 Department of Environmental Studies, New York University, New York, NY, USA

2 The CGIAR Research Program on Water, Land and Ecosystems, CGIAR, Colombo, Sri Lanka

3 Environment and Production Technology Division, International Food Policy Research Institute, Washington, DC, USA 


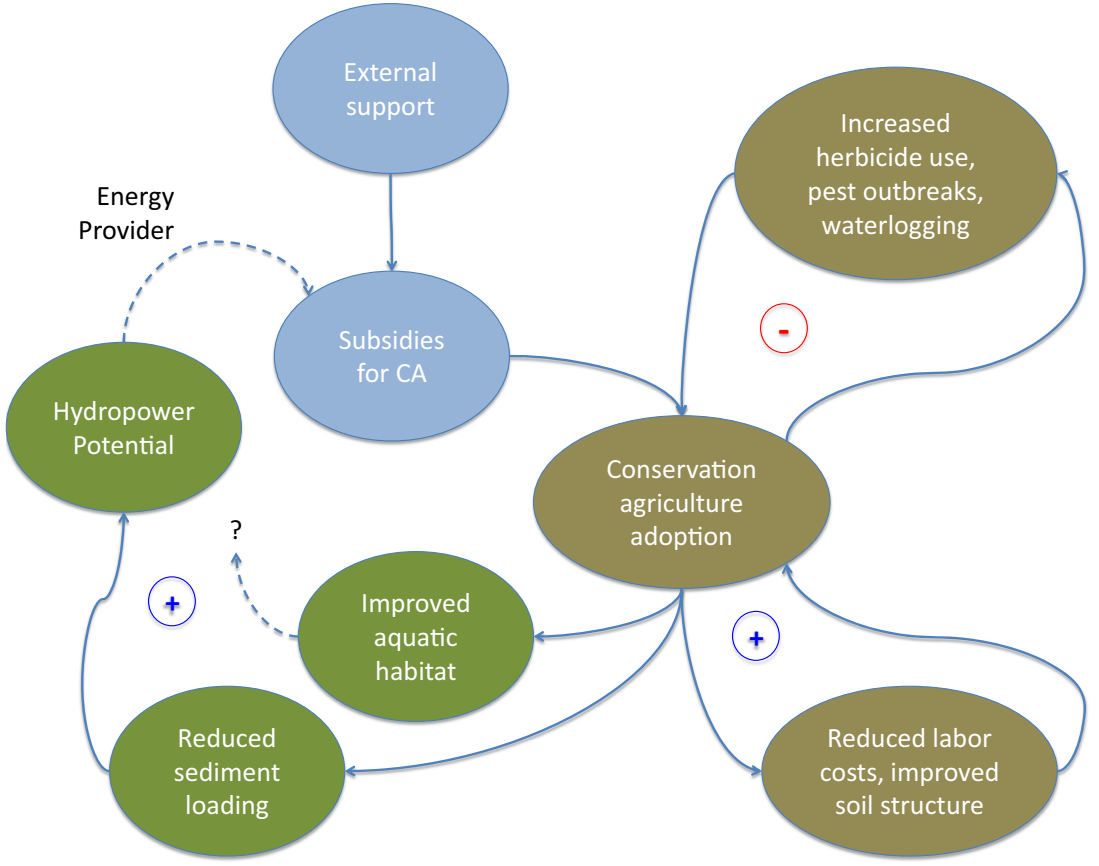

Fig. 3 Looking for options to close loop 3 in the Shire River Basin, Malawi (dashed lines)

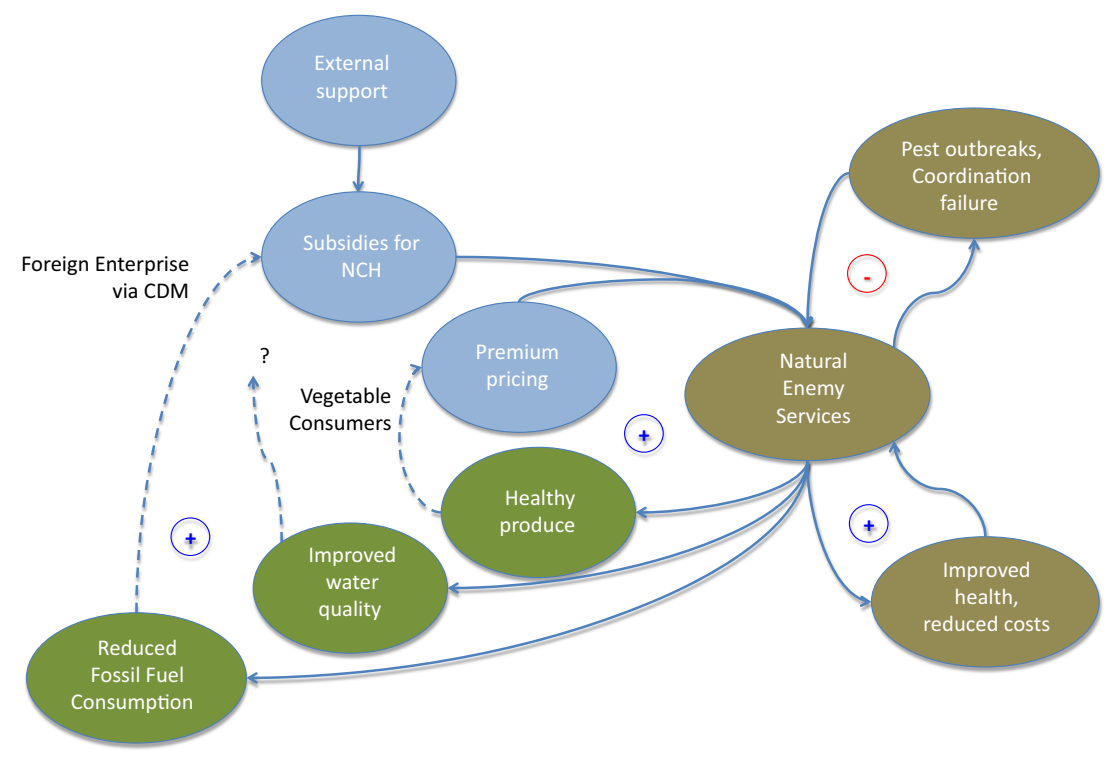

Fig. 4 Looking for options to close loop 3 in Southeast Asian IPM programs (dashed lines) 